\title{
El giro hermenéutico de Martín Lutero en la concepción de la iustitia Dei
}

Jorge Schulz

Universidad Nacional de San Martín / Seminario Internacional Teológico

Bautista, Argentina.

ORCID: 0000-0001-8933-7002

Recibido: 15 de marzo de 2021; aceptado: 3 de mayo de 2021

\begin{abstract}
Resumen
El hecho de que la doctrina de la justificación llegara a convertirse en el núcleo teológico fundamental de la Reforma y la tradición protestante ha estado estrechamente vinculado al descubrimiento de la justicia de Dios como acontecimiento de salvación. El presente artículo explora los límites de las concepciones clásicas de justicia con las que Martín Lutero (1483-1546) se encontró en su tiempo, y el modo en que la lectura de la Epístola a los romanos propició una nueva comprensión de la iustitia Dei y, consecuentemente, de la justificación por la fe. Al situar al Evangelio como clave interpretativa, se produce un desbordamiento de las nociones de justicia heredadas de la tradición filosófica en la medida que se retorna a las fuentes bíblicas. Este giro hermenéutico fue mucho más que un hecho anecdótico; representó un punto de inflexión no solamente para la labor de Lutero como reformador, sino también para el posterior desarrollo de la teología protestante.
\end{abstract}

PALABRAS CLAVE: MARTÍN LUTERO, JUSTICIA DE DIOS, REFORMA PROTESTANTE, EVANGELIO, JUSTIFICACIÓN.

\section{Martin Luther's Hermeneutic Turn in the Conception of the Iustitia Dei}

\begin{abstract}
The fact that the doctrine of justification became the fundamental theological core of the Reformation and the Protestant tradition has been closely linked to the discovery of God's justice as the event of salvation. This article explores the limits of the classical conceptions of righteousness that Martin Luther (1483-1546) encountered in his time, and the way in which the reading of the Epistle to the Romans led to a new understanding of iustitia Dei and, consequently, of justification by faith. By situating the Gospel as the interpretative key, there is an overcoming of the notions of justice inherited from the philosophical tradition to the extent that one returns to
\end{abstract}


the biblical sources. This hermeneutical turn was much more than an anecdotal event; it represented a turning point not only for Luther's work as a reformer, but also for the subsequent development of Protestant theology.

KEYWORDS: MARTIN LUTHER, RIGHTEOUSNESS OF GOD, PROTESTANT REFORMATION, GOSPEL, JUSTIFICATION.

\section{Introducción}

La Reforma Protestante surgió a partir de la crítica a la teología y las prácticas de la Iglesia Católica. Desde el punto de vista teológico, la cuestión se fue centrando en torno a una nueva noción de justicia y de la doctrina de la justificación que buscó retornar a una comprensión bíblica del concepto. La referencia a esta doctrina como "el artículo con el cual la Iglesia se mantiene en pie y se derrumba" (articulus stantis et cadentis ecclesiae) hace ver el lugar y la importancia decisiva que la doctrina de la justificación tuvo para los reformadores. Si bien, como señala Eberhard Jüngel, la expresión "articulus stantis et cadentis ecclesiae" formulada de esta manera no se encuentra en ninguno de los escritos de los reformadores, "Die Sachaussage aber ist genuin reformatorisch" (Jüngel, 2011: 13). En su Apologia Confessionis Augustanae, Felipe Melanchthon se refiere a la justificación por la fe como "el artículo supremo de la doctrina cristiana" (CA IV). ${ }^{1}$ En la segunda parte de los Articuli Smalcaldici, Martin Lutero comienza diciendo: "Este es el artículo primero y principal [...] Que Jesucristo, nuestro Dios y Señor fue entregado por nuestros pecados y resucitado para nuestra justificación" (ASm: 727.25-27); luego agrega: "sobre este artículo reposa todo lo que testificamos y hacemos" (ASm 729.10-11). ${ }^{2} \mathrm{Al}$ recorrer los distintos escritos de Lutero queda claro que, para el reformador, el artículo de la justificación no era simplemente uno más, sino el "maestro y príncipe, señor, rector y juez" (WA 39/1: 205) sobre todas las demás doctrinas, esencial para la existencia de la Iglesia y la posibilidad de vida en el mundo: "donde este artículo se diluye, allí se diluye también la Iglesia y ningún error podrá ya ser resistido" (WA 30/3: 319); "sin este artículo el mundo no es sino muerte y tinieblas" (WA 39/1: 205). ${ }^{3}$

La importancia de las partículas solo Christo, sola gratia, sola fide, sola scriptura -que la tradición protestante levantó como bandera- descansa en que estas llegaron a ser el refugio hermenéutico de una compresión evangélica de la doctrina de la justificación. En palabras de Jüngel, estas partículas representan "eine Reihe von Kriterien genannt, die theologiche Funktion haben, über die Reinheit der Rechtfertigungslehre zu wachen" (2011: 126). Pero el hecho de que la doctrina de la justificación se convirtiera en el centro teológico de mayor peso en la Reforma y la tradición protestante se debió en gran parte al descubrimiento de la justicia como un concepto de salvación. Lutero mismo narra cómo él proyectaba sobre el texto de Rm 1:17 una compresión de la iustitia Dei que respondía a una noción de justicia heredada de la tradición filosófica. La teología tardoescolástica en la cual se formó Lutero habría sido receptora de una manera de entender este término que pronto se convertiría para él en una clave hermenéutica conflictiva. Nos interesa aquí, en primer lugar, bosquejar muy brevemente el desarrollo de algunas nociones filosóficas de justicia para luego

\footnotetext{
1 Felipe Melanchthon, CA IV: 269.3: "praecipuus locus doctrinae Christianae". Las traducciones son propias salvo expresa indicación en contrario.

2 Martín Lutero, ASm: 727.25-27: "Hic primus et principalis articulus est [...] Quod Jesus Christus, Deus et Dominus noster, sit propter peccata nostra mortuus et propter justitiam nostram resurrexerit"; ibid. 729.10-11: "in hoc articulo sita sunt et consistunt omnia, quae [...] testamur et agimus".

3 Martín Lutero, WA 39/1: 205 "Articulus iustificationis est magister et princeps, dominus, rector, et iudex super omnia genera doctrinarum, qui conservat et gubernat omnem doctrinam ecclesiasticam et erigit conscientiam nostram coram Deo"; ibid. 30/3: 319: "wo der Artikel weg ist, so ist die Kirche weg, und mag keinem Irthum wiserstanden werden"; ibid. 39/1: 205: "Sine hoc articulo mundus est plane mors et tenebrae".
} 
contrastarla con el nuevo sentido redescubierto por el reformador. Esto nos invitará, finalmente, a indagar algunas informaciones exegéticas respecto al uso paulino de esta expresión, especialmente en su trasfondo hebreo. Sugerimos, de esta manera, que la tensión producida a partir de lectura de la Epístola a los romanos propició dicho giro hermenéutico en el cual el reformador termina rechazando las nociones heredadas de iustitia por una nueva comprensión de la justicia y de la doctrina de la justificación en clave evangélica.

\section{El concepto de justicia desde Platón y Aristóteles}

Las discusiones en torno a lo justo o lo injusto aparecen en muchos momentos a lo largo de los diálogos platónicos. Asimismo, la justicia es un concepto ampliamente trabajado en los escritos de Aristóteles. Las recepciones de Platón y Aristóteles en el pensamiento teológico-filosófico medieval que precedió a Lutero fueron configurando maneras de entender la justicia desde las cuales el reformador se acercó inicialmente a la lectura bíblica. No buscamos aquí realizar un análisis exhaustivo de este concepto en todo este espectro temporal, sino limitarnos a señalar aquellos rasgos más sobresalientes de las nociones clásicas de justicia y su posterior evolución en la tradición grecolatina y cristiana que pudieron haber desempeñado un rol importante en la hermenéutica de Lutero.

La crisis sociopolítica de la Atenas que llevó a la muerte a Sócrates movió fuertemente las preocupaciones filosóficas de Platón. En su pensamiento, la justicia es evocada como la virtud más importante que ha de mediar las relaciones de convivencia en la polis. A medida que Platón desarrolla su ideal de ciudad justa, el énfasis recae en el alto requerimiento que se le impone a la clase gobernante: la justicia es una virtud que no puede estar ausente en quienes dirigen los destinos de la ciudad. En el libro I de la República se problematizan diferentes aproximaciones al concepto de justicia y se discute sobre la importancia de no ceder ante nociones discrecionales como la de "hacer bien a los amigos y mal a los enemigos" (332d: 65) o entender lo justo como "lo que conviene al más fuerte" (338c: 76). ${ }^{4}$ En su obra, Platón sitúa a la justicia dentro de las cuatro virtudes cardinales, concibiéndola tanto en el ámbito político como en el individual. Mientras que las otras tres se asignan a una esfera del Estado o a alguna parte del alma, la justicia debe ser base de todas las demás. Es así que la noción de justicia se muestra en diferentes niveles. La polis es justa cuando individuos y clases de individuos -artesanos y agricultores, soldados y gobernantes- desempeñan su propia tarea en la comunidad. En el plano individual, la justicia se manifiesta cuando cada parte del alma desempeña su propia función. En tanto cada ámbito particular se mantiene en este orden, la justicia se exhibe universalmente como la síntesis de todas las virtudes. Para ello es preciso evitar "dispersarse en muchas tareas"; más bien "cada uno debe ocuparse de una sola cosa de cuantas conciernen al Estado, aquella para la cual la naturaleza lo hubiera dotado mejor" (Rep. 433a: 223). ${ }^{5}$ En definitiva, para Platón "la justicia ha de consistir en hacer lo que corresponde a cada uno de modo adecuado" (433b: 223) o, como se expresa más adelante, "la justicia consiste tanto en tener cada uno lo propio como en hacer lo suyo" (434a: 224$){ }^{6}$

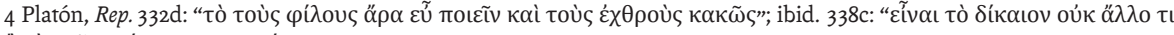

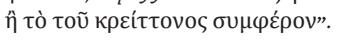

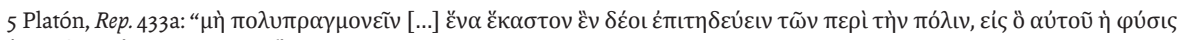

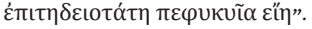

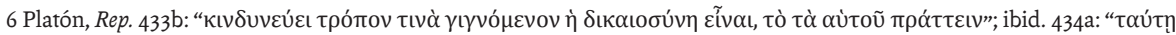

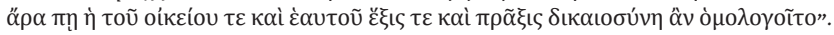


También Aristóteles concibe a la justicia como "la más excelente de las virtudes" (EN 1129b: 239). ${ }^{7}$ Citando las Elegías de Teognis, expresa que "ni el atardecer ni la aurora son tan maravillosos" como ellas (ibid.) y, trayendo un antiguo proverbio, agrega: "en la justicia están incluidas todas las virtudes" (ibid.). ${ }^{8}$ Un primer aspecto a destacar es que el estagirita refuerza el elemento relacional al considerar que la justicia es "la virtud en el más cabal sentido" o "la virtud perfecta" (ibid.) solo en la medida en que organiza el comportamiento hacia la otra persona, es decir, en tanto está referida al bien ajeno y es utilizada en "la difícil tarea" de procurar también el beneficio de los demás y no solo el de uno mismo (EN 1130a: 239). ${ }^{9}$ En el pensamiento aristotélico aparece una serie de distinciones mediante las cuales se conciben diversas formas de justicia que se sitúan en el plano legal. Si bien Platón al final de su vida había reconocido la necesidad de las leyes, Aristóteles enfatiza la legalidad al entender a la justicia como "la virtud por la que cada uno tiene lo suyo conforme a la ley" ( $R h$. 1366b 5: 243). ${ }^{10}$ De esta manera, la justicia distributiva busca fijar la proporcionalidad con las que se han de distribuir las recompensas y los castigos acorde a los méritos, en donde "lo justo es la proporción y lo injusto lo que va contra la proporción" (EN $1131 \mathrm{~b}$ 15: 245). ${ }^{11}$ También se habla de justicia conmutativa mediante la cual se regula la igualdad en el intercambio de bienes o contratos. Por otra parte, Aristóteles utiliza expresiones como justicia correctiva, punitiva o retributiva que hacen referencia a una compensación que se exige en función de los perjuicios ocasionados. En todas estas distinciones se observa un esfuerzo por resguardar el principio de igualdad y compensación bajo criterios legales.

La enseñanza aristotélica transmitió básicamente una doble comprensión: la justicia entendida en un sentido general como la suma de las virtudes puesta en práctica de cara a la otra persona, y la justicia entendida en su sentido legal. El influjo de esta doble comprensión se ve reflejada también en las tradiciones posteriores. La Stoa y la filosofía popular romana concibió la justicia como una cualidad que abarca toda la vida, vinculando lo justo con lo noble, lo bueno, lo apropiado. Cicerón expresa que es "en la justicia donde mejor brilla la virtud; aquella por la que los hombres son declarados buenos" (De officiis I.7) ${ }^{12} \mathrm{Y}$ en un sentido específicamente jurídico la definición de Ulpiano adquiere una importancia decisiva: "la justicia es la constante y perpetua voluntad de conceder a cada uno su derecho" (Frg. D.1.10.10). ${ }^{13}$

En el pensamiento cristiano será decisivo tanto el significado teológico como el éticopolítico de la justicia. También la posición que se adopte sobre la doctrina de la salvación jugará un rol muy importante. En general, la ética patrística ha conservado la doctrina tradicional de las virtudes cardinales y entre ellas a la justicia. Lactancio aborda la justicia desde la regla de oro, que consiste en tomar como criterio de nuestra propia conducta hacia los demás aquellas formas de actuación que quisiéramos que se consideren hacia nosotros. ${ }^{14}$ Hans Reiner observa que esta norma -que llegó a

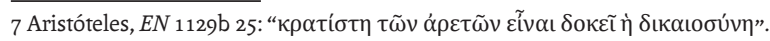

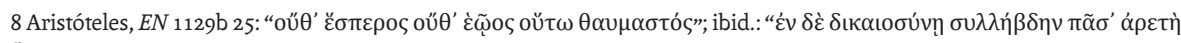
हैvı".

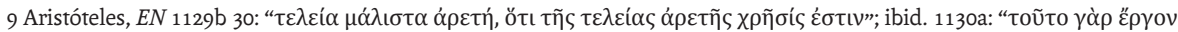
$\chi \alpha \lambda \varepsilon \pi$ von" $^{2}$

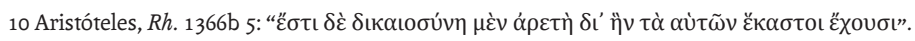

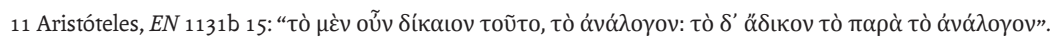

12 Cicerón, De officiis I.7: “iustitia, in qua virtutis est splendor maximus, ex qua viri boni nominantur”.

13 Ulpiano, Frg. D.1.10.10: "iustitia est constans et perpetua voluntas ius suum unicuique tribuendi".

14 Lactancio, Divin. inst. VI.12: 524.15: "Haec est illa perfecta iustitia quae custodit humanam de qua philosophi locuntur societatem, hic diuitiarum maximus ac uerissimus fructus est, non uti opibus ad propriam unius uoluptatem, sed ad multorum salutem, non ad praesentem suum fructum, sed ad iustitiam, quae sola non interit” [trad. Sánchez Salor, 1990: 217: Esta es la perfecta justicia que mira por esa sociedad humana de la que hablan los filósofos; este es el más grande y autentico fruto de las riquezas: hacer uso de ellas, no para el propio placer de uno solo, sino para el bien de muchos; no para obtener un fruto propio momentáneo, sino para alcanzar la justicia, que es la única que no perece]. 
estar ampliamente extendida en la mayoría de los pueblos civilizados desde el siglo V a.C.- se remonta al Antiguo Testamento (Tb 4:15) siendo luego retomada por Jesús ( $\mathrm{Mt}$ 7:12; Lc 6:31). Este autor señala que en la tradición griega esta regla estuvo presente como "ley natural" aunque con distintas formulaciones, y que Pablo la reivindicará en $\operatorname{Rm} 2: 14-16{ }^{15}$

Ambrosio hace también algunas correcciones cristianas y, siguiendo a Cicerón, presenta la justicia como una virtud social en el marco de las virtudes cardinales (cf. De officis min. I.28). Aun Agustín mantiene la justicia como una virtud cívica dentro de las cuatro virtudes básicas, elogiándola tanto en sus escritos tempranos como en sus posteriores homilías. La justicia, "cuyo objeto es dar a cada uno lo suyo" (De civ. Dei XIX.4.4), ${ }^{16}$ representa aquí la armonía de todas las virtudes en tanto que expresa, además, el correcto orden en la relación del ser humano con Dios y consigo mismo: "de aquí que en el mismo hombre haya un orden natural justo: el alma se somete a Dios y la carne al alma" (ibid.). ${ }^{17}$ Pero un aspecto que no puede soslayarse es el hecho que teólogos de la época patrística -como Agustín, Ambrosio o Basilio- no conciben a la justicia al margen de la gracia de Dios. A menudo se contrasta la propia justicia por la ley o la disposición natural con la justicia que proviene de la gracia. Esta justicia, como un don inmerecido, tiene que ver más con la remisión de pecados que con la perfección virtuosa, y solo encuentra su consumación en el amor del reino de Dios: "hay, por lo tanto, justicia plena cuando hay salud plena, y hay salud plena cuando hay amor pleno. Por eso, el amor es la plenitud de la ley. Habrá amor pleno cuando le veamos tal cual es" (De perf. iust. hom. III.8). ${ }^{18}$

En el pensamiento medieval se suele abordar el tema de la justicia desde tres ángulos: desde la justicia como un atributo de Dios, desde la justificación del pecador y desde la justicia moral del ser humano. La teología de los autores y escuelas retoman y conservan conceptos de la filosofía antigua para definir los atributos y los actos de Dios sin perder el horizonte de los enunciados bíblicos. Anselmo de Canterbury entiende el concepto de justicia desde la noción de rectitud óntica de la que participan todos los demás seres y mediante la cual llegan a ser rectos. En De veritate sostiene que la justicia moral se funda y está determinada por la rectitud de la voluntad: "Así pues, llamamos correctamente justicia a la rectitud de la voluntad que se observa por la rectitud misma" (DVXII). ${ }^{19}$ Tomás de Aquino trata con gran detalle la virtud moral de la justicia. Al abordarla en su Summa Theologiae, la sitúa entre las demás virtudes cardinales adquiridas y toma como punto de partida la citada definición de Ulpiano. Tomás se basa en Aristóteles para definir a la justicia como hábito que dispone a obrar y querer lo justo; entiende, además, la justicia -siguiendo a Anselmo- como la rectitud de la voluntad (cf. STh II-II, q. 58). Dado que la justicia busca ordenar al ser humano (tanto individual como comunitariamente) en sus relaciones con otros,

15 Reiner, 1977: 232: "Lehre von einem uns vom Logos der Allnatur eingepflanzten sittlichen Gesetz, einer lex naturae, haben (nach Anfängen bei den Sophisten, Platon und Aristoteles) bekanntlich die Stoiker und Cicero ausgebildet. Eine Verbindung dieser Lehre mit der Goldenen Regel und ihrem umfassenden Anspruch beginnt sich im Römerbrief des Apostels Paulus herzustellen".

16 Agustín, De civ. Dei XIX.4.4: 666.92-93: "cuius munus est sua cuique tribuere". En De libero arbitrio (I.13.27: 228.12-14) Agustín se pregunta "Iam iustitiam quid dicamus esse nisi uirtutem, qua sua cuique tribuuntur?" [¿Qué hemos de decir, finalmente, de la justicia, sino que es la virtud que manda dar a cada uno lo suyo?] afirmando luego que nada hay mejor que ella. También en una de sus homilías (Sermo CL.8.9: 812) declara: "Est virtus animi res laudabilis, prudentia mala et bona discernens, justitia sua cuique distribuens, temperantia libidines cohibens, fortitudo molestias aequanimiter sustinens. Magna res, laudabilis res" [La virtud del alma es cosa digna de alabanza; tanto la prudencia que discierne el bien y el mal como la justicia que distribuye a cada uno lo suyo, o la templanza que refrena las pasiones o la fortaleza que soporta serenamente las molestias. Es cosa grande y digna de alabanza].

17 Agustín, De civ. Dei XIX.4: 666.93-94: "unde fit in ipso homine quidam iustus ordo naturae, ut anima subdatur Deo et animae caro".

18 Agustín, De perf. iust. hom. III.8: 8.2-5: “Tunc ergo plena iustitia, quando plena sanitas; tunc plena sanitas, quando plena caritas -plenitudo enim legis caritas- tunc autem plena caritas, quando uidebimus eum sicuti est”.

19 Anselmo, DV XII: 196.19-20: "Bene igitur diximus iustitiam esse rectitudinem voluntatis servatam propter se". 
Tomás distingue tres tipos de justicia: conmutativa, distributiva y generalis. En todas ellas se busca resguardar el principio de igualdad en los vínculos de convivencia. La iustitia conmutativa regula el intercambio, la distributiva establece los criterios participación, y la generalis establece las leyes que han de ser obedecidas por los miembros de una comunidad.

\section{El giro hermenéutico en Lutero}

En 1545, un año antes de la muerte de Lutero, se publicó en Wittenberg una edición de sus obras. Lutero, ya anciano, escribió un prefacio para el primer volumen de esta edición en el que aprovechó para reflexionar sobre sus primeros años en Wittenberg. En este repaso retrospectivo y autobiográfico Lutero reflexionó sobre el problema teológico que, según nos dice, lo había estado perturbando durante un período de tiempo considerable. La dificultad del reformador se centraba en la comprensión de la expresión "justicia de Dios" presente en el texto de Rm 1:17: "Porque en el Evangelio la justicia de Dios se revela por fe y para fe, como está escrito: mas el justo por la fe vivirá". En un relato apasionado Lutero escribe sus memorias en las siguientes palabras:

Miro certe ardore captus fueram cognoscendi Pauli in epistola ad Rom., sed obstiterat hactenus non frigidus circum praecordia sanguis, sed unicum vocabulum, quod est Cap. I: Iustitia Dei revelatur in illo. Oderam enim vocabulum istud 'Iustitia Dei', quod usu et consuetudine omnium doctorum doctus eram philosophice intelligere de iustitia (ut vocant) formali seu activa, qua Deus est iustus, et peccatores iniustosque punit. Ego autem, qui me, utcunque irreprehensibilis monachus vivebam, sentirem coram Deo esse peccatorem inquietissimae conscientiae, nec mea satisfactione placatum confidere possem, non amabam, imo odiebam iustum et punientem peccatores Deum, tacitaque si non blasphemia, certe ingenti murmuratione indignabar Deo, dicens: quasi vero non satis sit, miseros peccatores et aeternaliter perditos peccato originali omni genere calamitatis oppressos esse per legem decalogi, nisi Deus per evangelium dolorem dolori adderet, et etiam per evangelium nobis iustitiam et iram suam intentaret. Furebam ita saeva et perturbata conscientia, pulsabam tamen importunus eo loco Paulum, ardentissime sitiens scire, quid S. Paulus vellet (WA 54: 185).

Yo estaba, ciertamente, poseído por un extraordinario anhelo de entender a Pablo en su Carta a los romanos; pero entonces se interpuso en el camino un solo vocablo que se halla en el capítulo 1: "la justicia de Dios se revela en él" [en el Evangelio]. En efecto, yo aborrecía esa palabra "justicia de Dios" que yo había aprendido a entender filosóficamente, según el uso y la costumbre de todos los doctores: como si se tratara de la justicia formal o activa, según la cual Dios es justo y castiga a los pecadores y a los injustos. Pero yo [...] no amaba, yo aborrecía al Dios que es justo y castiga a los pecadores; pero con secreta, si no blasfema, pero sí ingente murmuración estaba indignado con Dios y [me] decía: "como si no fuera bastante el que los pobres pecadores, que se han perdido eternamente por el pecado original, estén cargados con toda clase de infortunios por el Decálogo, ¡Dios tuvo que añadir ahora sufrimiento al sufrimiento y, por medio del Evangelio, quiso volver también su justicia y su ira contra nosotros!". Me hallaba así furioso, con una cruel y consternada conciencia. Sin embargo, yo recurría llamando insistentemente a aquel pasaje de Pablo, y sentía ardiente sed de saber lo que Pablo quiso decir (WA 54).

Como se ha visto en la sección anterior, desde Platón y Aristóteles la concepción de justicia ha estado atravesada por la idea de dar a cada uno lo suyo. La posterior influencia que tuvo el antiguo derecho romano sobre el mundo en el que se forjó la primera teología de la Iglesia de habla latina hizo inevitable que la interpretación romana de la naturaleza de la justicia se proyectara sobre el término iustitia en las Escrituras. 
Esto se debe al hecho que desde sus orígenes el cristianismo -a diferencia las otras religiones monoteístas- no contó con una legislación propia tendiente a la regulación de la vida social, por lo cual en su ordenamiento jurídico la Iglesia fue adaptando los esquemas seculares del derecho romano a sus propósitos teológicos. Ahora bien, cuando el uso del término iustitia -cargado de los matices propios del mundo romano- se transfiere al contexto teológico, la cuestión deviene en un equívoco en el cual la noción bíblica de justicia divina termina por asimilarse a las nociones seculares predominantes en el derecho. De esta manera, la consecuencia no puede ser otra más que la gradual aparición de la creencia de que Dios, al actuar con justicia, distribuye recompensas o castigos a las personas según merezcan sus obras. En este escenario, y para una persona tan consciente de sus propios pecados y de que "no hay justo, $\mathrm{ni}$ aun uno" ( $\mathrm{Rm}$ 3:10), ¿cómo podría la revelación de la justicia de Dios ser una buena noticia? Según narra Lutero, es en medio de esta crisis donde se produjo en él un giro hermenéutico que llegará a ser una de las intuiciones fundamentales de la Reforma:

Donec miserente Deo meditabundus dies et noctes connexionem verborum attenderem, nempe: Iustitia Dei revelatur in illo, sicut scriptum est: Iustus ex fide vivit, ibi iustitiam Dei coepi intelligere eam, qua iustus dono Dei vivit, nempe ex fide, et esse hanc sententiam, revelari per evangeliam iustitiam Dei, scilicet passivam, qua nos Deus misericors iustificat per fidem, sicut scriptum est: Iustus ex fide vivit. Hic me prorsus renatum esse sensi, et apertis portis in ipsam paradisam intrasse. lbi continuo alia mihi facies totius scripturae apparuit. [...] Iam quanto odio vocabulum 'iustitia Dei' oderam ante, tanto amore dulcissimum mihi vocabulum extollebam, ita mihi iste locus Pauli fuit vere porta paradisi (WA 54: 186).

Hasta que Dios se apiadó de mí, que estaba cavilando día y noche, y me di cuenta de la conexión de las palabras, a saber, que la justicia de Dios se revela en él, según está escrito: El justo por la fe vivirá. Entonces comencé a comprender la justicia de Dios: [como la justicia] por la cual vive el que es justo por un don de Dios, a saber, por la fe. Y este sería el sentido, por medio del Evangelio, la justicia de Dios se revela como justicia pasiva, con la cual el Dios misericordioso nos hace justos por medio de la fe, tal como está escrito: El justo por la fe vivirá. Entonces me sentí como si hubiera nacido enteramente de nuevo y hubiese entrado, con las puertas abiertas de par en par en el paraíso mismo. Entonces toda la Escritura me mostró un semblante distinto. [...] Tan grande como había sido el aborrecimiento con el que yo había detestado antes los vocablos "justicia de Dios", así de grande era ahora el amor con el que yo apreciaba ahora esa palabra como la más dulce para mí. Así fue como este pasaje de Pablo se convirtió verdaderamente para mí en la puerta del paraíso (WA 54).

La intuición fundamental de Lutero fue la de situar el Evangelio como la clave hermenéutica de la justicia de Dios. El Evangelio es el lugar donde la justicia de Dios se muestra en su significado soteriológico; como sostiene Jüngel, "das Evangelium entscheidet, was Gottes Gerechtigkeit bedeutet" (2011: 58). A partir de este giro en la concepción de la iustitia Dei, Lutero deja atrás una concepción punitiva de justicia para entenderla como un acontecimiento de salvación por medio de la fe, cuya gratuidad tiene un decisivo fundamento cristológico. Entre 1515 y 1516 Lutero pronunció una serie de lecciones sobre la Epístola a los romanos. En su comentario preparado para aquella ocasión -y precisamente en referencia a Rm 1:17- expresa lo siguiente:

In humanis doctrinis reuelatur et docetur Iustitia hominum, i. e. quis et quomodo sit et fiat Iustus coram se et hominibus. Sed in solo euangelio reuelatur Iustitia Dei (i.e. quis et quomodo sit et fiat Iustus coram Deo) per solam fidem, qua Dei verbo creditur. [...] Iustitia enim Dei est causa salutis. Et hic iterum 'Iustitia Dei' non ea debet accipi, qua ipse Iustus est in seipso, Sed qua nos ex ipso Iustificamur, quod fit per fidem euangelii. [...] Et dicitur ad differentiam Iustitie hominum, que ex operibus fit. Sicut Aristoteles 3. 
Ethicorum manifeste determinat, secundum quem Iustitia sequitur et fit ex actibus. Sed secundum Deum precedit opera et opera fiunt ex ipsa (WA 56: 171-172).

En las enseñanzas humanas se revela e inculca la justicia de los hombres, es decir, se enseña quién es y de qué naturaleza es el justo ante sí mismo y ante los demás, y cómo se llega a serlo. Pero en ningún otro lugar sino en el Evangelio se revela la justicia de Dios (es decir, quién es y de qué naturaleza es el justo ante Dios, y cómo se llega a serlo) por medio de la fe sola con que el hombre cree la palabra de Dios. [...] Pues la justicia de Dios es la causa de la salvación. Y aquí "justicia de Dios" no debe entenderse como aquella por virtud por la cual él es justo en sí mismo, sino la justicia por la cual nosotros somos hechos justos por Dios, lo cual ocurre por medio de la fe en el Evangelio. [...] La justicia de Dios debe distinguirse de la justicia de los hombres que proviene de las obras, como indica claramente Aristóteles en el tercer capítulo de su Ética. Según él, la justicia es el resultado de las obras, y se origina en ellas. Pero para Dios, la justicia precede a las obras, de modo que las obras son el resultado de la justicia (WA 56).

Lutero había comenzado su actividad como un teólogo típico de la época medieval tardía, preocupado por la reforma de las creencias y las prácticas de la Iglesia. Las corrientes que más contribuyeron en su formación teológica fueron el humanismo, el nominalismo y la orden agustiniana (a la cual pertenecía). Alister McGrath realiza un análisis de estas fuentes en el pensamiento temprano de Lutero, mostrando que desde 1509 hasta 1514 su hermenéutica bíblica había permanecido bajo los cánones de la via moderna.$^{20} \mathrm{El}$ punto de inflexión que comenzará a marcar la ruptura de Lutero con estos teólogos -al menos en lo que concierne a la doctrina de la justificación-será el periodo que se abre a partir de las mencionadas lecciones sobre la Epístola a los romanos $(1515-1516){ }^{21}$

Lutero sigue reconociendo la importancia de una iustitia civilis que rige la buena conducta según las normas de una ley externa, sin embargo, en cuanto a la justicia en su sentido teológico, toma distancia de las concepciones filosóficas clásicas que se habían asimilado en el pensamiento teológico tardomedieval. Marc Lienhard (1973) ha ayudado a estructurar las diferentes etapas en el pensamiento del reformador, mostrando cómo Lutero rompe con la piedad cristológica medieval basada en la contemplación e imitación moralizante, para afirmar con mayor radicalidad que la condición pecadora no deja lugar a ningún acto meritorio con el cual el ser humano pueda contribuir a su propia salvación. De manera que las nociones que abordaban la justicia como habitus o como qualitas animae son ahora consideradas por el reformador como completamente inadecuadas en el contexto teológico. Aquí ya no hay lugar para una praeparatio ad gratiam según la concepción ockhamista (Ebeling, 1960: 501), dado que ello favorecería la premisa de que la salvación depende de las obras humanas. Para Lutero la gracia no era un hábito del alma ni una especie de ente metafísico que se infunde en el ser humano. La gracia es para el reformador la misericordia que Dios siente por los pecadores y que, a pesar de sus pecados, lo mueve a actuar en pro de la salvación de ellos. Es así que en este giro también se observa una transformación en la imagen de Dios. Lutero ya no concibe a Dios como un ser abstracto e impasible, sino como una persona divina con quien es posible entrar en relación mediante la fe en Jesucristo. Pero la fe, a su vez, no es aquí entendida como un mero asentimiento racional de doctrinas, sino -fundamentalmente- como un gesto de confianza personal.

20 McGrath, 2011: 140 "Luther is only familiar with the theology of the moderni, such as William of Ockham, Pierre d'Ailly, and Gabriel Biel, at first hand, and shows little familiarity with other theologians".

21 McGrath, 2011: 181-182: "There are two good reasons for suggesting that Luther does not remain within the shared theological matrix of his age, developing instead a theology of justification which can only be described as Luther's own creation. The first of these reasons relates to Luther's espousal of the servum arbitrium, which goes far beyond Augustine's statements on the incapacitation of the human free will by sin. The second, and more significant, relates to the development of the concept of iustitia Christi aliena, unquestionably one of the most original and creative aspects of Luther's mature doctrine of justification". 
En este giro hermenéutico el elemento retributivo-punitivo no desaparece completamente, sino que se desplaza hacia el concepto de ley, configurando así una tensión fundamental en el pensamiento de Lutero que se expresa en la dialéctica ley-Evangelio. Para el reformador la ley no concede una justicia que pueda ser formada por el hábito. Las obras de la ley no pueden justificar al ser humano, su función se orienta más bien a poner al descubierto su condición pecadora. La ley sigue siendo la expresión de la voluntad de Dios, pero cuando el pecador se percata que de su impotencia para vivir conforme a ella es cuando se prepara el terreno para la recepción del Evangelio. El incumplimiento de la ley por parte del ser humano produce culpabilidad, pero esta carga es asumida por Cristo.

La teología de la cruz que Lutero desarrolla se muestra en estrecha relación con su nueva comprensión de la justicia de Dios. La cruz es interpretada como un sacrificio expiatorio mediante el cual Jesucristo toma el lugar del pecador recibiendo sobre sí el castigo de la ley que este merecía. La buena noticia del Evangelio es que el creyente que se une a Cristo por medio de la fe ya no se encuentra expuesto a la condenación de la ley ni a la ira de Dios, sino que en virtud de esta sustitución ha sido justificado. De esta manera la justicia de Dios llega a ser una buena noticia sobre la base de una teoría de la expiación en la que el elemento punitivo queda absorbido por Jesucristo. Por ello Lutero habla del acontecimiento de la cruz como un alegre intercambio (fröhlisches Wechsel): Cristo asume la condenación de la ley y la justicia de Cristo le es imputada al creyente. Es así que la justificación tiene lugar a partir de la relación con Cristo, y es esta relación la que vivifica al ser humano haciendo posible la consecución de las buenas obras. La justicia de Dios es para el reformador un don extra nos. El creyente justificado vive de la donación de una justicia que él mismo es incapaz de producir, como lo afirma en Von der Freiheit eines Christenmenschen: "un cristiano no vive en sí mismo; vive en Cristo y en su prójimo: en Cristo por la fe, en el prójimo por el amor" (WA 7:38). ${ }^{22}$

\section{El concepto bíblico de justicia evocado en Romanos 1:17}

Al indagar por el sentido de la expresión "justicia de Dios" en las Escrituras y específicamente en su uso paulino, es preciso atender a la profunda vinculación y dependencia

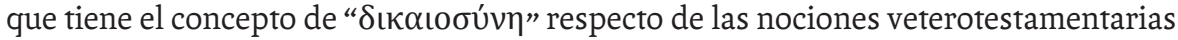
de justicia expresadas principalmente mediante el término hebreo "הקד" (tzedaká). En este punto Pablo no fue innovador, por lo que explorar la riqueza que está detrás de este término es provechoso para profundizar el sentido de esta justicia que se revela en el Evangelio. Al abordar el tema de la justicia de Yahvé, Gerhard von Rad, uno de los más importantes teólogos del Antiguo Testamento, señala:

Es gibt im Alten Testament keinen Begriff von so zentraler Bedeutung schlechthin für Lebensbeziehungen des Menschen wie den der הקדצ. Er ist der Maßtab nicht nur für das Verhältnis des Menschen zu Gott, sondern auch für das Verhältnis der Menschen untereinander bis hin zu den belanglosesten Streitereien, ja auch für das Verhältnis des Menschen zu den Tieren und zu seiner naturhaften Umwelt. הקדצ kann man ohne weiteres als den höchsten Lebenswert bezeichnen, als das, worauf alles Leben, wenn es in Ordnung ist, gründet (von Rad, 1962: 368).

De acuerdo al testimonio del Antiguo Testamento, las referencias a la justicia de Dios se mueven siempre dentro de un horizonte soteriológico. Esta expresión nada tiene que ver con un concepto jurídico, sino que apela siempre a las gestas salvadoras de

22 Martín Lutero, WA 7: 38: "ein Christenmensch nicht in sich selbst lebt, sondern in Christus und seinem Nächsten. In Christus durch den Glauben, im Nächsten durch die Liebe”. 
Yahvé. Walter Brueggemann la define como "By righteousness we mean Yahweh's ready capacity to be present in situations of trouble and to intervene powerfully and decisively in the interest of rehabilitation, restoration, and well-being" (Brueggemann, 2005: 130).

La justicia de Dios tiene que ver con una relación comunitaria que Dios ofrece a su pueblo al brindarse en una alianza de vida. La fidelidad de Dios a la comunidad es el fundamento de esta comunión porque es la fuerza que crea las condiciones y sustenta las posibilidades de que el pueblo responda a su vez comunitariamente (cf. Stuhlmacher, 1968: 117; Wilckens, 1997: 215). Todas las relaciones del pueblo están determinadas en lo fundamental por la relación con Dios. Dios mismo es el fundamento vital que da sustento en todas las dimensiones relacionales de la vida.

La justicia de Dios es un espacio comunitario que Dios abre y en el cual Dios se abre de cara a su pueblo, ordenando de tal modo las circunstancias y las relaciones vitales que las personas allí integradas obtienen sus derechos sin tener ellas mismas que apropiárselos por sus propios medios y a costa de los derechos de los demás (cf. Jüngel, 2011: 45). La justicia de Dios es una comunión creadora y sustentadora de vida. Fuera de ella el pueblo es incapaz de con-vivir. Solo en ella la vida humana es realizable. Solo al estar en esa común unión con Dios se puede llegar a ser personas plenamente humanas, porque la paz (שלום) es fruto de su justicia (Is 32:17). La ley tiene la función de velar por esta alianza de vida. La ley instruye en el camino de justicia buscando el resguardo de la integridad de los vínculos comunitarios, y haciendo cognoscible las infidelidades relacionales como transgresión.

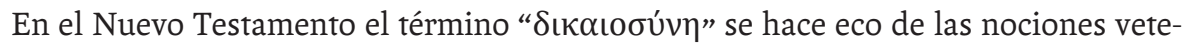
rotestamentarias de justicia tornándose polisémica de acuerdo con los usos y matices de los distintos autores. Esto sucede en el caso de la teología paulina. La expresión

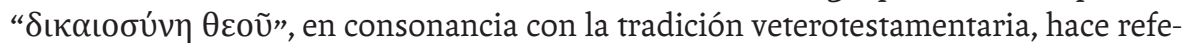
rencia a los actos salvíficos de Dios. Sobre esta noción Pablo señala que el acontecer de la justicia de Dios no está determinado por el quehacer humano, sino que responde exclusivamente a la gracia de Dios y la fe en Jesucristo.

El genitivo "de Dios" $(\theta \varepsilon$ coũ), en tanto genitivo subjetivo, hace referencia a la justicia como un atributo del ser de Dios: Dios es justo. Pero las veces que Pablo usa la

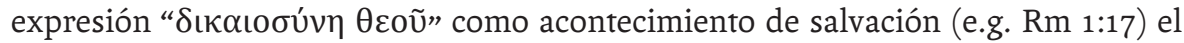
acento recae en el genitivo $\theta \varepsilon$ coũ como un genitivo de autor. ${ }^{23}$ En esta dirección, la justicia de Dios hace referencia a la justicia que Dios produce. Sin embargo, en el fondo ambos genitivos se encuentran teológicamente integrados, de tal manera que se podría pensar en la justicia de Dios como el desborde de su ser en su hacer salvífico, dado que la justicia en el testimonio bíblico no es una mera propiedad privada que Dios se reserva para sí mismo, sino un atributo que busca comunicarse para crear relaciones de salvación.

El concepto de justicia evocado por Rm 1:17 lejos está de las nociones retributivaspunitivas de la tradición filosófica. La justicia en el texto bíblico no está afirmando la imagen de un Dios "justiciero" o vengativo. Muy por el contrario, en el Evangelio la justicia de Dios se manifiesta como proyecto de salvación, como logró intuir Lutero en su giro hermenéutico. Aunque los exégetas señalan que al desarrollar la doctrina de justificación Pablo hace uso de terminología forense, hay que tener presente el trasfondo hebreo de su teología. De modo que cuando Pablo hace referencia a la acción mediante la cual Dios justifica, hay al menos un doble sentido que quisiéramos destacar aquí: el sentido forense de la terminología empleada y el sentido que apunta 
a la rehabilitación de las relaciones. Justificar en un sentido forense implica declarar justo. Esto consiste en una palabra de Dios que viene desde afuera del sujeto y perdona los pecados. Justificar en un sentido rehabilitador implica una regeneración de los tejidos relacionales y comunitarios que habían sido rotos por el pecado. Se trata de una acción de Dios creadora de comunión, que tiene efectos transformadores en el interior del creyente y que lo capacita para volver a estar en correcta relación con Dios, consigo mismo y con su entorno social y natural.

\section{Conclusiones}

Según el testimonio que él mismo da en sus escritos, Lutero había asimilado una noción de justicia heredada de la tradición filosófica que resultó en un equívoco al momento de entender la expresión "iustitia Dei" en las Escrituras. La resolución de esta interpretación conflictiva resultó en un giro hermenéutico de enormes implicancias no solamente para Lutero como reformador sino para la teología de la Reforma en general. Al situar el Evangelio como la clave interpretativa, el reformador recupera el significado teológico y-sobre todo- soteriológico de la justicia, superando así las concepciones clásicas dominantes en su tiempo. Esta intuición de Lutero, confirmada en lo esencial por la exégesis bíblica, fue el germen inicial de un cambio de perspectiva en la doctrina de la justificación, que terminará por consolidarse como el núcleo teológico fundamental del protestantismo: la justificación por gracia y mediante fe en Jesucristo.

El giro hermenéutico del reformador respecto al concepto de justicia nos invita, además, a pensar en la relación y la diferencia entre concepciones provenientes de la tradición filosófica y la tradición de la teología protestante. En ambas tradiciones la justicia aparece como un concepto de relación, es decir, un concepto mediador de las relaciones a los efectos de posibilitar un espacio para el desarrollo humano. Sin embargo, hay profundas diferencias. Lutero rechaza radicalmente el fundamento antropológico de las concepciones filosóficas de justicia, ya que estas desconocen el problema del pecado, que es un problema fundamental en la antropología teológica. En efecto, el reformador pasará a concebir la justicia desplazando su polo de actividad constituyente hacia afuera del sujeto, para pensar las obras del creyente no como una condición a priori de la justificación sino como consecuencia a posteriori de la fe.

En la tradición de los filósofos y juristas el acento del concepto de justicia permanece más en el plano de la legalidad y tiene la función de resguardar el principio de igualdad en los distintos modos de organización cívica. En Lutero, desde el ángulo del Evangelio, la justicia desborda la mera legalidad en virtud de la gracia de Dios. La iustitia Dei llega a ser para el reformador una buena noticia ya que, lejos de ser un concepto punitivo, refiere a un don inmerecido que de ninguna manera el ser humano podría regalarse a sí mismo. Como escribe Lutero a Georg Spenlein en una carta del 8 de abril de 1516: “Tú, Señor Jesús, eres mi justicia; yo en cambio, tu pecado. Tú has tomado sobre ti lo que es mío, y me has regalado lo que es tuyo. Tú has tomado sobre ti lo que tú no eras y me has regalado lo que yo no era" (WA 1:17). ${ }^{24}$

24 Martín Lutero, WA 1:17: “du, Herr Jesus, bist meine Gerechtigkeit, ich aber bin deine Sünde; du hast das Meine auf dich genommen und mir das Deine gegeben; du hast angenommen, was du nicht warst, und mir gegeben, was ich nicht war". 


\section{Bibliografía}

\section{Fuentes}

\section{Ediciones}

» Augustinus Hipponensis (1845). Sermones ad populum. Ed. Migne, J.-P. París. (PL 38).

" Augustinus Hipponensis (1902). De Perfectione lustitiae Hominis. Eds. Vrba, C. F. y Zycha, I. Viena. (CSEL 42).

"Augustinus Hipponensis (1955). De ciuitate Dei. Eds. Dombart, B. y Kalbe, A. Turnhout: Brepols. (CCSL 48).

» Augustinus Hipponensis (1970). Contra academicos. De beata vita. De ordine. De magistro. De libero arbitrio. Eds. Green, W. M y Daur, K. D. Turnhout: Brepols. (CCSL 29).

"Anselmus Cantuariensis (1946). De Veritate. En: Ed. Schmitt, F. S. Opera omnia I. Edimburgo: Thomas Nelson and Sons.

" Aristotelis (2010). Ethica Nicomachea. Ed. Bywater, I. Cambridge: Cambridge University Press.

》Aristotelis (1959). Ars Rhetorica. Ed. Ross, W. D. Oxford: Clarendon Press.

" Cicero (1913). De officiis / On Duties. Ed. bilingüe. Trad. Miller, W. Londres: Heinemann.

» Lactantius (1890). L. Caeli Firmiani Lactanti Opera Omnia. Eds. Brandt, S. y Laubmann, G. Vindobonae: F. Tempsky.

" Martin Luther (1883-1929). D. Martin Luthers Werke: Kritische Gesamtausgabe (Weimarer Ausgabe). Weimar: H. Böhlaus Nachfolger.

» Martin Luther (2014). Articuli Smalcaldici. En: Eds. Dingel, I. et al., Die Bekenntnisschriften der evangelisch-lutherischen Kirche. Gotinga: Vandenhoeck \& Ruprecht.

" Philipp Melanchthon (2014). Confessio Augustana. En: Eds. Dingel, I. et al., Die Bekenntnisschriften der evangelisch-lutherischen Kirche. Gotinga: Vandenhoeck \& Ruprecht.

»Plato (1903). Platonis Opera. IV. Ed. Burnet, J. Oxford: Oxford University Press.

"Tomás de Aquino (2014). Suma teológica. Edición bilingüe. Eds. María Ramírez, S., Barbado Viejo, F y Urdánoz, T. Madrid: BAC.

»Ulpianus (1845). Domitii Vlpiani qvae vocant Fragmenta: Sive Excerpta ex Vlpiani Libro singulari regularvm. Ed. Böcking, E. Bonn: Impensis Adolphi Marci.

\section{Traducciones}

»Agustín de Hipona (1982). Del libre albedrío. Trad. Seijas, E. Obras de San Agustín III. Madrid: BAC.

»Agustín de Hipona. (1984). La perfección de la justicia del hombre. Trad. Calvo, T. 
Obras de San Agustín XXXV. Madrid: BAC.

» Agustín de Hipona (1988). La ciudad de Dios. Trads. Santamarta del Río, S. y Fuertes Lanero, M. Obras de San Agustín XVI-XVII. Madrid: BAC.

"Agustín de Hipona (1983). Sermones (3\%). Trad. De Luis Vizcaíno, P. Obras de San Agustín XXIII. Madrid: BAC.

》 Aristóteles (1999). Retórica. Trad. Racionero, Q. Madrid: Gredos.

» Aristóteles (2003). Ética nicomáquea; ética eudemia. Trad. Pallí Bonet, J. Madrid: Gredos.

» Lactancio (1990). Instituciones divinas. Libros IV-VII. Trad. Sánchez Salor, E. Madrid: Gredos.

»Platón (1988). Diálogos IV: República. Trad. Eggers Lan, C. Madrid: Gredos.

\section{Bibliografía complementaria}

» Brueggemann, W. (2005). Theology of the Old Testament: Testimony, dispute, advocacy. Minnesota: Fortress Press.

" Bultmann, R. (1981). Teología del Nuevo Testamento. Trad. Martínez de Lapera, V. A. Salamanca: Ediciones Sígueme.

"Cranfield, C. E. B. (2004). A critical and exegetical commentary on the Epistle to the Romans. Londres - Nueva York: T\&T Clark International.

»Ebeling, G. (1960). "Martin Luther". En: Galling, K. et al. (ed.). Die Religion in Geschichte und Gegenwart, 3 Auflage, Bd. 4. Tubinga: Mohr Siebeck.

»Jüngel, E. (2011). Das Evangelium von der Rechtfertigung des Gottlosen als Zentrum des christlichen Glaubens: Eine theologische Studie in ökumenischer Absicht. Tubinga: Mohr Siebeck.

» Käsemann, E. (1994). Commentary on Romans. Trad. Bromiley, G. W. Michigan: William B. Eerdmans.

» Lienhard, M. (1973). Luther, temoin de Jesus-Christ: les etapes et les themes de la christologie du reformateur. París: Éd. du Cerf.

» McGrath, A. E. (2011). Luther's theology of the cross: Martin Luther's theological breakthrough. Oxford - Massachusetts: Wiley-Blackwell.

» Reiner, H. (1977). "Die Goldene Regel und das Naturrecht: Zugleich Antwort auf die Frage: Gibt es ein Naturrecht?", Studia Leibnitiana 9.2, 231-254.

"Stuhlmacher, P. (1968). Gerechtigkeit Gottes bei Paulus. Gotinga: Vandenhoeck \& Ruprecht.

"Von Rad, G. (1962). Theologie des Alten Testaments. 1: Die Theologie der geschichtlichen Überlieferungen Israels. Múnich: Kaiser.

»Wilckens, U. (1997). La Carta a los Romanos: Rom. 1-5. Trad. Martínez de Lapera, V. A. Salamanca: Ediciones Sígueme. 
